\title{
Perbandingan Unjuk Kerja Tangki Penyimpan Energi Termal Stratifikasi Dengan Variasi Diameter Difuser
}

\author{
Wahyu Hidayat, Joko Waluyo, Khasani \\ Jurusan Teknik Mesin dan Industri Universitas Gadjah Mada \\ Jalan Grafika No. 2, Yogyakarta 55281 \\ Telepon : +62-274-521673, Fax: +62-274-521673 \\ E-mail : ingga.wahyu@yahoo.com
}

Intisari

Sistem kogenerasi yang dikenal dengan combined heat and power (CHP) merupakan teknologi yang digunakan untuk menghasilkan energi termal selain energi utama yang berupa energi listrik. Energi termal dihasilkan dengan memanfaaatkan gas yang terbuang dari cerobong pada temperatur yang masih tinggi. Pemanfaatan sistem kogenerasi bisa dikategorikan dalam dua jenis, yaitu untuk energi pemanas (district heating) dan untuk pengkondisian udara (dictrict cooling). Untuk mengatur distribusi penggunaan energi sesuai dengan kebutuhan beban rendah dan beban tinggi, sistem kogenerasi memerlukan tangki penyimpan energi termal (PET) stratifikasi. Tangki PET digunakan karena memiliki konstruksi yang sederhana dan mempunyai unjuk kerja yang handal. Unjuk kerja tangki PET pada penelitian ini dilakukan terhadap variasi diameter difuser. Penelitian menggunakan pengujian eksperimen pada tangki berbentuk silinder dengan difuser berbentuk radial. Variasi penelitian dilakukan dengan tiga diameter difuser yang berbeda $(80 \mathrm{~mm}, 120 \mathrm{~mm}$,dan $120 \mathrm{~mm})$. Penentuan unjuk kerja tangki PET stratifikasi dilakukan dengan mengamati ketebalan termoklin menggunakan formulasi matematis dengan analisa distribusi temperatur menggunakan persamaan SDR (Sigmoid Dose Response). Hasil penelitian menunjukkan hasil unjuk kerja yang paling handal terhadap difuser dengan diameter 160mm. Hal ini menunjukkan pencampuran air dingin dan air panas terpengaruh oleh mekanisme aliran saat air panas memasuki tangki PET. Aliran masuk yang tenang dan halus akan memperkecil terbentuknya termoklin.

Kata kunci : Tangki PET stratifikasi, unjuk kerja, difuser, ketebalan termoklin

\section{Pendahuluan}

Sistem kogenerasi atau juga dikenal dengan nama combined heat and power (CHP) merupakan teknologi yang digunakan untuk menghasilkan energi termal selain energi utama yang berupa energi listrik. Energi termal dihasilkan dengan memanfaaatkan gas buang dari cerobong yang masih memiliki temperatur tinggi. Pemanfaatan sistem kogenerasi dikategorikan dalam dua jenis, yaitu untuk energi pemanas (district heating) dan untuk pengkondisian udara (dictrict cooling). Pada aplikasi kogenerasi power plant system energi termal dihasilkan oleh HRSG (Heat Recovery Steam Generator) dimana panas yang terbuang dari cerobong exhaust turbin gas dimanfaatkan untuk memanaskan air, kemudian air panas disimpan dalam suatu Penyimpan Energi Termal (PET) (Horlock,1987). Dengan demikian didapat energi pemanas yang murah di power plant system karena memanfaatkan panas yang terbuang.

Energi pemanas ini dimanfaatkan untuk memanaskan air yang akan digunakan untuk menggerakkan turbin pada sebuah power plant system tenaga uap. Beban power plant system umumnya mencapai beban puncak pada siang hingga sore hari, sebaliknya akan menurun menjelang tengah malam. Untuk mengoptimalkan pengaturan beban, diperlukan suatu tangki yang mampu menyimpan energi termal di malam hari agar bisa digunakan di siang hingga sore harinya. Untuk keperluan tersebut, tangki penyimpan termal stratifikasi umumnya digunakan karena mempunyai kelebihan konstruksi yang sederhana namun mempunyai unjuk kerja yang handal (Waluyo,2012).

Konsep kerja tangki PET stratifikasi adalah dengan menyimpan air panas dan air dingin pada satu 
tangki tanpa ada penghalang secara fisik. Aliran air panas dilewatkan di nosel bagian atas, sedangkan air dingin disirkulasikan melalui di nosel bagian bawah. Dengan prinsip kerja seperti ini maka unjuk kerja tangki penyimpan termal stratifikasi sangat terpengaruh oleh mekanisme pemisahan antara air dingin di bagian bawah dan air panas di bagian atas tangki (Waluyo,2012). Bentuk distribusi temperature air di dalam tangki ini menyerupai kurva $\mathrm{S}$, yang sangat berpengaruh untuk penentuan unjuk kerja tangki (Wang,2000). Ilustrasi bentuk distribusi suhu menyerupai kurva S diperlihatkan pada Gambar 1. Terlihat pada Gambar 1 tersebut bahwa air dingin berada di bagian bawah tangki dan air panas di bagian atas tangki. Sedangkan area pencampuran antara air panas dan air dingin yang disebut termoklin terletak di bagian tengah.

Beberapa konsep parameter unjuk kerja tangki penyimpan termal stratifikasi sudah dikembangkan antara lain berupa ketentuan ketebalan termoklin $\left(W_{T C}\right)$ dan Figure of Merit setengah $\left(F_{o M_{1 / 2}}\right)$ (Musser A dan Bahnfleth,1998).Unjuk kerja tangki PET stratifikasi yang handal ditunjukkan dengan tipisnya termoklin $\left(W_{T C}\right)$ yang terbentuk dan Figure of Merit setengah $\left(F O M_{1 / 2}\right)$ yang nilainya mendekati satu. Penentuan unjuk kerja yang tersedia saat ini dilakukan dengan melakukan capturing temperatur yang didapatkan dari pencatatan langsung untuk mendapatkan profil distribusi suhu (Waluyo,2012). Dengan cara ini sulit didapatkan hitungan unjuk kerja yang akurat karena kesulitan estimasi terhadap profil distribusi temperatur. Dengan kata lain, karena belum adanya representasi matematis distribusi suhu air di dalam tangki menyebabkan terkendalanya formulasi unjuk kerja tangki penyimpan energi termal stratifikasi.

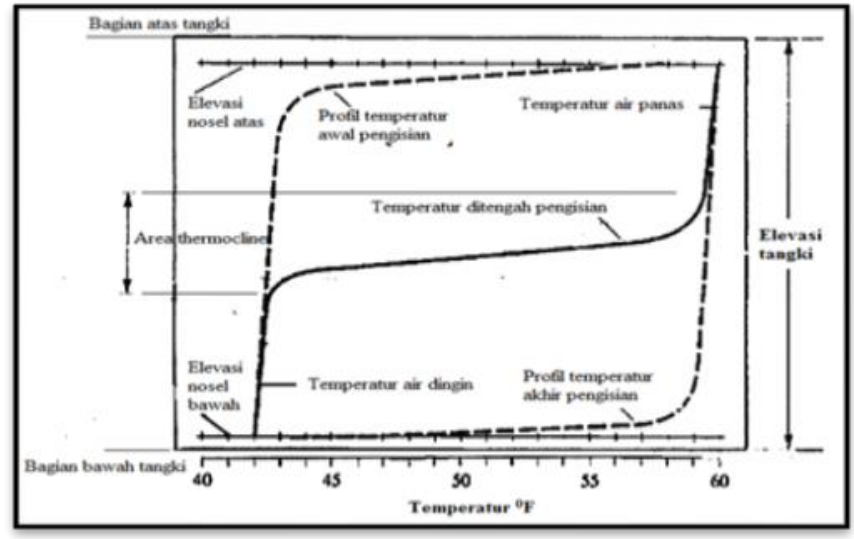

Gambar 1. Kurva S distribusi suhu (Wang,2000)

Penelitian ini ditujukan untuk melakukan pengukuran temperatur yang dilakukan secara periodis untuk rentang waktu tertentu selama pengisian. Hasil pengukuran temperatur dikonversi ke profil persamaan SDR. Penentuan unjuk kerja tangki PET stratifikasi ditentukan dari ketebalan termoklin yang diturunkan dari formulasi matematis persamaan SDR. Analisa penentuan unjuk kerja dilakukan dengan membandingkan ketebalan termoklin pada pengisian PET stratifikasi dengan berbagai diameter difuser.

\section{Metodologi}

Penelitian mengenai karakterisasi distribusi temperatur pada tangki PET stratifikasi ini dilakukan dengan menggunakan tangki PET stratifikasi dengan diameter $200 \mathrm{~mm}$ dan tinggi $1200 \mathrm{~mm}$ seperti yang diperlihatkan pada Gambar 3B. Pada penelitian ini digunakan kepala tangki dengan diameter $200 \mathrm{~mm}$ yang dipasang diatas tangki PET stratifikasi untuk menaikkan unjuk kerja dari tangki PET stratifikasi tersebut, gambaran bentuk kepala tangki tersajipada gambar 3A. Difuser yang digunakan adalah difuser jenis radial dengan arah semburan ke arah samping dengan variasi diameter $80 \mathrm{~mm}, 120 \mathrm{~mm}$, dan $160 \mathrm{~mm}$ yang gambaran bentuk difusernya disajikan pada Gambar 3C. Debit yang digunakan pada penelitian ini adalah 1,22 liter/jam. Tahapan-tahapan pengambilan data pada penelitian ini adalah sebagai berikut : 


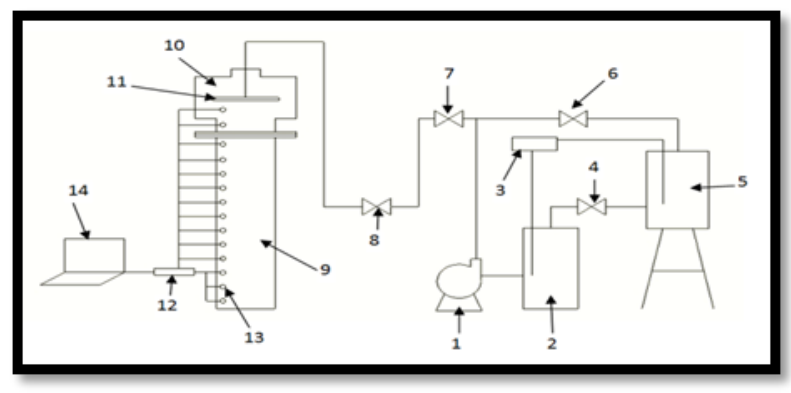

Gambar 2. Skema Instalasi Penelitian

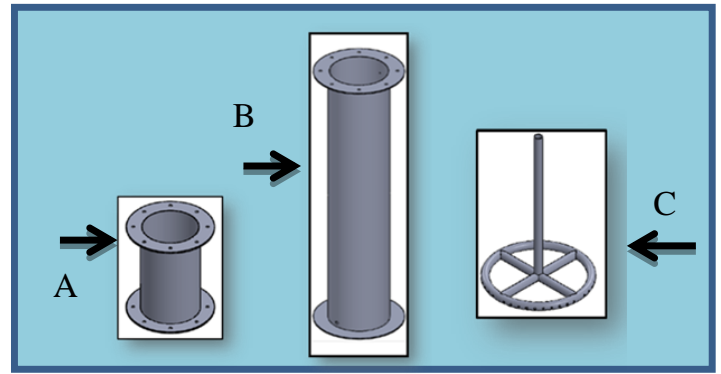

Gambar 3. A.(Kepala tangki) B.(Tangki PET Stratifikasi) C.(Difuser Radial)

\begin{tabular}{|ll|}
\hline \multicolumn{2}{|c|}{ Keterangan Gambar 2} \\
1.Pompa & 8.Gate Valve \\
2.Tangki Pemana & 9.Tangki Utama PET \\
3.Control Temperatur & 10.Kepla Tangki \\
4.Valve & 11.Difuser \\
5.Tangki Penampung & 12.Data logger Termokopel \\
6.by pass valve & 13.Termokopel \\
7. Valve & 14.PC \\
\hline
\end{tabular}

1. Perancangan dan pembuatan tangki PET stratifikasi

2. Melakukan set-up peralatan penelitian.

3. Melakukan proses kalibrasi terhadap termokopel.

4. Mengisi air pada bak penampungan air (reservoir) dan bak pemanas.

5. Sebelum melakukan pengisian pada bak penampung dan bak pemanas air perlu disaring terlebih dahulu agar kotoran tidak masuk ke dalam tangki.

6. Menutup katup menuju valve gate dan membuka penuh katup by pass pompa.

7. Melakukan setting controler temperatur pada temperatur $50^{\circ} \mathrm{C}$ yang ada dalam bak pemanasan dan menghidupkan pemanas air.

8. Menghidupkan pompa untuk sirkulasi air agar temperatur air cepat merata padatemperatur $50^{\circ} \mathrm{C}$.

9. Menyeting record temperatur pada komputer setiap durasi satu menit.

10. Membuka perlahan - lahan katup pada valve gate hingga didapatkan debit yang diinginkan.

11. Setelah debit yang diinginkan didapat maka proses mengalirkan air menuju difusser, kepala tangki, dan tangki PET bisa dilakukan.

12. Menentukan parameter :

i. Tentukan nilai $T_{c}$ dan $T_{h}$ kemudian cari harga $C$ dan $S$ dengan menggunakan sigmaplot.

ii. Formulasikan nilai $W_{T c}$, dan $F_{o M} M_{1 / 2}$ dengan persamaan Sigmoid Dose Respone (SDR)

13. Ganti difuser dengan bentuk yang berbeda dan lakukan kembali langkah langkah yang telah dilakukan di atas.

\section{Parameter Distribusi Temperatur}

Seperti dijelaskan pada Gambar 1 bahwa profil distribusi suhu air di dalam tangki menyerupai kurva S. Sisi datar bawah merupakan air dingin, sisi datar atas merupakan air panas sedangkan di area lengkungan disebut termoklin yang merupakan area campuran air panas dan dan air dingin. Untuk melakukan karakterisasi terhadap distributsi suhu tersebut, dilakukan pendefinisian berbagai parameter kurva S. Ilustrasi penentuan parameter kurva S disajikan pada Gambar 4. 


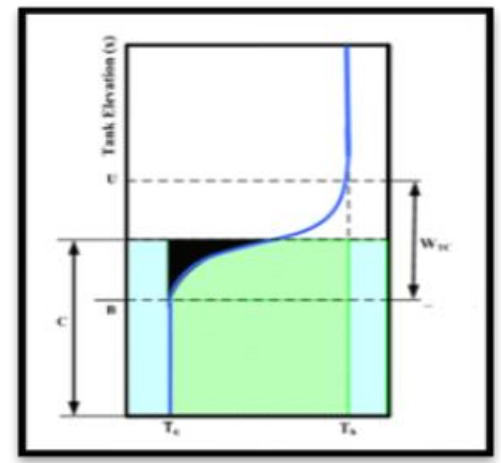

\section{Keterangan Gambar 4}

1.Batas bawah termoklin adalah B

2.Batas atas termoklin adalah $\mathrm{U}$

3.Suhu rata-rata air dingin adalah $T_{c}$.

4.Suhu rata-rata air panas adalah $T_{h}$

5.Posisi tengah termoklin adalah $C$

6.Gradien kelengkungan termoklin adalah $S$

7.Ketebalan termoklin adalah $W_{T C}$

Gambar 4. Parameter Di Dalam Kurva S (Joko Waluyo,2011)

Dari Gambar 4, dapat dijelaskan bahwa profil distribusi suhu merupakan fungsi 4 parameter yaitu $T_{c}$, $T_{h}, C$ dan $S$, serta merupakan fungsi dari variabel elevasi tangki (x). Mengacu kepada hal tersebut, maka fungsi distribusi suhu dapat dituliskan sebagai berikut :

Persamaan matematis yang gunakan adalah persamaan Sigmoid Dose Response (SDR) dengan kriteria mampu merepresentasikan profil kurva $\mathrm{S}$ serta berisikan 4 buah parameter $T_{h}, T_{c}, C$ dan $S$ yang merupakan fungsi elevasi kedalaman air (X).

Persamaan Sigmoid Dose Response (SDR) dituliskan sebagai berikut :

$$
T=T_{c}+\frac{T_{h}-T_{c}}{1+10^{(C-X) S}}
$$

Persamaan SDR menghubungkan distribusi temperatur dengan 4 parameter $T_{c}, T_{h}, C$ and $S$, dan variabel elevasi air $(\mathrm{X})$. Parameter $T_{c}$ dan $T_{h}$ adalah temperatur rata-rata air dingin dan panas $\left({ }^{\circ} \mathrm{C}\right)$. Parameter $C$ adalah angka tak berdimensi titik tengah dari ketebalan termoklin, sedangkan $S$ adalah gradien kelengkungan dari termoklin dan variabel $X$ menyatakan elevasi tak berdimensi $(X=x . N / H)$.

Dimana, $\quad \mathrm{x} \quad$ : elevasi di titik tengah slab (m)

$\mathrm{H} \quad$ : kedalaman efektif air di dalam tangki (m)

$\mathrm{N} \quad$ : jumlah slab di dalam tangki.

\section{Parameter Unjuk Kerja Tangki PET}

Persamaan SDR dapat digunakan untuk menjabarkan beberapa parameter unjuk kerja tangki PET stratifikasi antara lain ketebalan termoklin $\left(W_{T C}\right)$ dan Figure of Merit setengah $\left(F_{o M_{1 / 2}}\right)$. Untuk tujuan tersebut digunakan suatu parameter suhu tak berdimensi yang didefinisikan sebagai $\Theta=\left(T-T_{c}\right) /\left(T_{h}-T_{c}\right)$. Parameter ini didapatkan dengan mengadopsi ketentuan suhu cut-off tak berdimensi. Selanjutnya dengan menggunakan persamaan SDR, dapat diperoleh formulasi beberapa parameter suhu air di dalam tangki sebagai berikut :

\section{Ketebalan Termoklin $\left(W_{T C}\right)$}

Salah satu hal yang menunjukkan apakah unjuk kerja suatu tangki PET stratifikasi handal atau tidak adalah dari tebal atau tipisnya termoklin. Ketebalan termoklin didefinisikan sebagai lebar dari area percampuran antara air panas dan air dingin. Ketebalan termoklin $\left(W_{T C}\right)$ dibatasi oleh batas atas $(U)$ dan batas bawah $(B)$. Untuk melakukan kajian ini rumusan temperatur cut -off $\Theta=\left(T-T_{c}\right) /\left(T_{h}-T_{c}\right)$, digunakan untuk menunjukkan ujung profil thermoklin.

Dengan demikian ketebalan termoklin $\left(W_{T C}\right)$ bisa dirumuskan sebagai berikut

$W_{T C}=\frac{2 \cdot \log \left(\frac{1}{\Theta}-1\right)}{S}$

\section{Half-cycle Figure of Merit $\left(\right.$ FoM $\left._{1 / 2}\right)$}


FoM $M_{1 / 2}$ adalah tolak ukur efisiensi termal tangki PETstratifikasi karena kehilangan rugi konduksi dan efek pencampuran.

Rumusan dari Figure of Merit setengah (FoM $\left.{ }_{1 / 2}\right)$ dituliskan sebagai berikut :

$F o M_{1 / 2}=1-\left(C_{\text {Lost }} / C_{\text {Max }}\right)$

$C_{\text {Lost }}$ adalah hasil pengurangan kapasitas teoritis penyimpanan termal $\left(C_{\text {Max }}\right)$ dengan kapasitas aktual penyimpanan termal $\left(C_{\text {int. }}\right)$. Rumusan ini menyisakan kelemahan hasil yang kurang akurat karena harus melibatkan capturing distribusi temperatur yang harus terukur di lapangan. Rumusan ini perlu disempurnakan dengan formulasi matematis untuk memperoleh hitungan Figure of Merit Setengah secara eksak di dalam pengoperasian tangki PET stratifikasi.

Formulasi Figure of Merit setengah diperoleh dari penyelesaian integral dari persamaan (3) dengan persamaan SDR, formulasi $C_{\text {Max }}$ didapatkan sebagai berikut :

$C_{\text {Max }}=\rho \cdot A \cdot C_{p} \cdot C \cdot\left(T_{h}-T_{C}\right)$

Formulasi $C_{\text {Lost }}$ dilakukan dengan menyelesaikan integral persamaan kontinyu

$C_{\text {Lost }}=A \cdot \rho \cdot C_{p} \cdot \int_{B}^{L}\left(T_{x}-T_{c}\right) \cdot d x$ dan substitusi ke persamaan $T_{x}=T_{C}+\frac{T_{h 2}-T_{C}}{1+10^{(C-X) S}}$.

$C_{\text {Lost }}=A \cdot \rho \cdot C_{p} \cdot\left(T_{h}-T_{c}\right) \cdot\left[X+\frac{\log \left(1+10^{(C-X) S}\right)}{S \cdot \log 10}\right]^{C}$

\section{Hasil dan Pembahasan}

Berdasarkan penelitian yang telah dilakukan tentang perbandingan unjuk kerja tangki penyimpan energi termal stratifikasi dengan variasi diameter difuser didapatkan hasil sebagai berikut :

Pengambilan data pada penelitian ini dilakukan dengan menggunakan debit 1,22L/jam dan variasi penelitian menggunakan variasi difuser berbentuk radial dengan diameter $80 \mathrm{~mm}, 120 \mathrm{~mm}$,dan $160 \mathrm{~mm}$. Pengolahan data pada penelitian ini menggunakan persamaan Sigmoid Dose Respone yang diselesaikan menggunakan sigmaplot. Gambar plotting fungsi SDR menggunakan sigmaplot pada penelitian ini di paparkan pada Gambar 5.

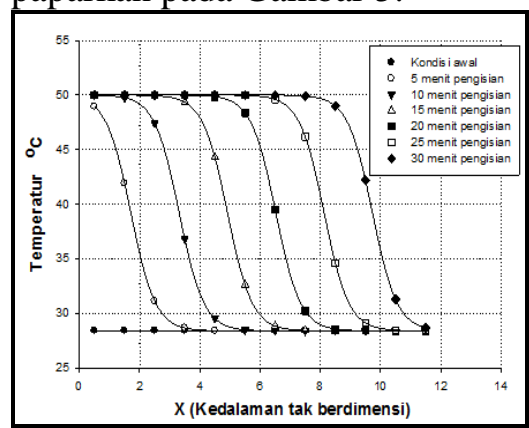

A

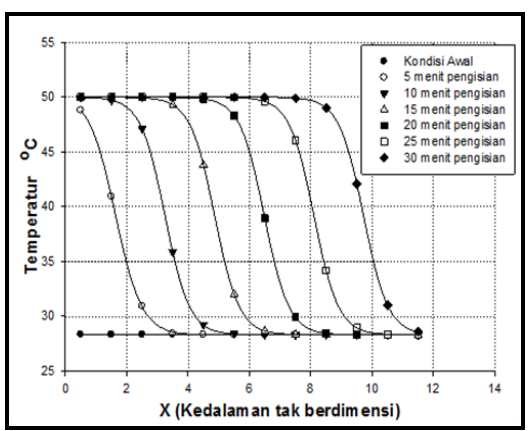

B

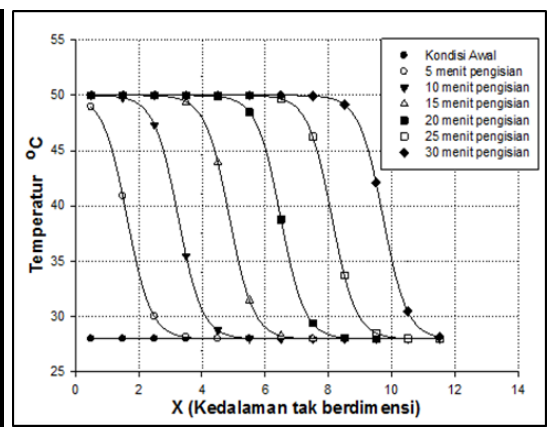

$\mathrm{C}$

Gambar 5. Plotting Fungsi SDR A. $(\varnothing 80 \mathrm{~mm})$ B. $(\varnothing 120 \mathrm{~mm})$ C. $(\varnothing 160 \mathrm{~mm})$

\section{Perbandingan Ketebalan Termoklin ( $\left.W_{T C}\right)$ dan Figure of Merit $\left(\right.$ FoM $\left._{1 / 2}\right)$}

Salah satu parameter yang menunjukkan apakah unjuk kerja suatu tangki PET stratifikasi handal atau tidak adalah dari tebal atau tipisnya termoklin $\left(W_{T C}\right)$. Pada gambar dipaparkan perbedaan nilai ketebalan termoklin dari tiga buah difuser dengan debit yang sama. FoM $M_{1 / 2}$ adalah tolak ukur efisiensi termal tangki PET stratifikasi karena kehilangan rugi konduksi dan efek pencampuran. FoM $M_{1 / 2}$ termasuk juga salah satu parameter yang menunjukkan unjuk kerja tangki PET stratifikasi selain ketebalan termoklin $\left(W_{T C}\right)$. Nilai dari termoklin dan $F o M_{1 / 2}$ pada penelitian ini disajikan pada Tabel 1. Perbandingan nilai termoklin $\left(W_{T C}\right)$ untuk $\varnothing 80 \mathrm{~mm}, \varnothing 120 \mathrm{~mm}$,dan $\emptyset 160 \mathrm{~mm}$ pada penelitian ini disajikan pada Gambar 6 sedangkan untuk perbandingan nilai $F o M_{1 / 2}$ nya diasajikan pada gambar 7 . 
Tabel 1.

Nilai $W_{T C}$ dan $F_{o M_{1 / 2}}$ Untuk Diameter 80mm,120mm,Dan 160mm

\begin{tabular}{|c|c|c|c|c|c|c|}
\hline \multirow{2}{*}{ Menit Ke } & $\varnothing$ Difuser $80 \mathrm{~mm}$ & Ø Difuser $120 \mathrm{~mm}$ & $\varnothing$ Difuser $160 \mathrm{~mm}$ & $\varnothing$ Difuser $80 \mathrm{~mm}$ & Ø Difu ser $120 \mathrm{~mm}$ & $\varnothing$ Difuser $160 \mathrm{~mm}$ \\
\hline & $W_{T C}$ & $W_{I C}$ & $W_{I C}$ & $\mathrm{FoM}_{1 / 2}$ & $\mathrm{FoM}_{1 / 2}$ & $\mathrm{FoM}_{1 / 2}$ \\
\hline 5 & 0 & 0 & 0 & 0 & 0 & 0 \\
\hline 10 & 1.7995 & 1.7569 & 1.6677 & 0.92643 & 0.9267 & 0.9305 \\
\hline 15 & 1.8013 & 1.7578 & 1.669 & 0.9506 & 0.9513 & 0.9538 \\
\hline 20 & 1.8 & 1.756 & 1.6668 & 0.96285 & 0.9636 & 0.9654 \\
\hline 25 & 1.7995 & 1.7578 & 1.6695 & 0.97023 & 0.9708 & 0.9723 \\
\hline 30 & 1.8017 & 1.7587 & 1.6695 & 0.97513 & 0.9757 & 0.9769 \\
\hline
\end{tabular}

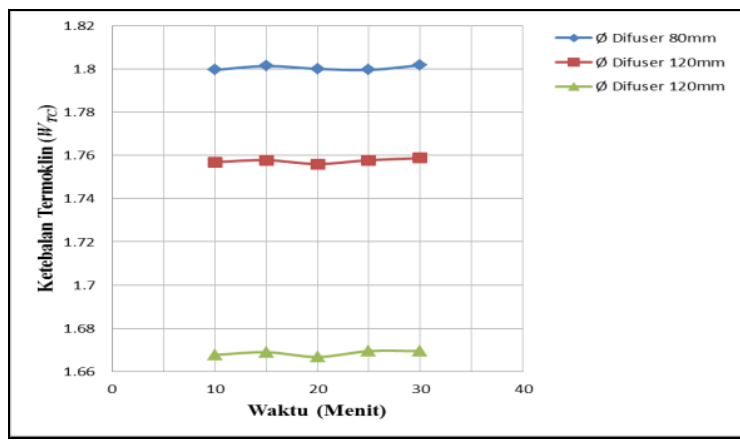

Gambar 6. Grafik Nilai $W_{T C}$

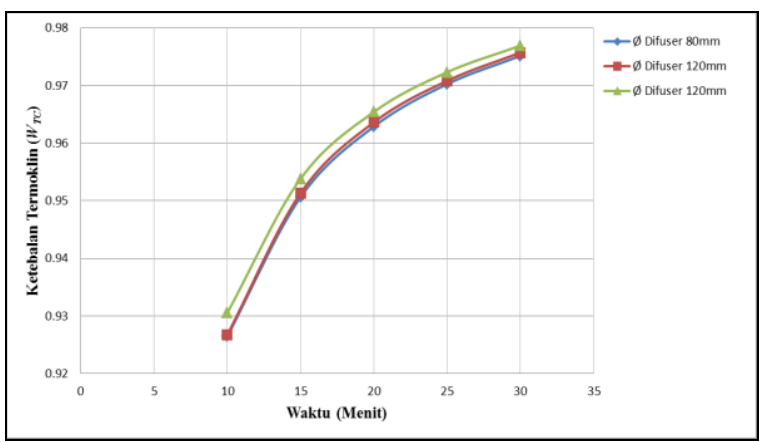

Gambar 7. Grafik $\left(\mathrm{FoM}_{1 / 2}\right)$

\section{Kesimpulan}

Dari hasil penelitian ini dapat disimpulkan bahwa karakterisasi pengujian unjuk kerja tangki PET stratifikasi dengan variasi diameter yang dilakukan pada debit 1,22liter/jam didapatkan hasil, difuser dengan $\varnothing 160 \mathrm{~mm}$ mempunyai ketebalan termoklin yang lebih tipis dan nilai $F_{0 M_{1 / 2}}$ yang lebih besar dibandingkan dengan difuser dengan $\varnothing 80 \mathrm{~mm}$ dan $\emptyset 120 \mathrm{~mm}$. Dengan dua parameter tersebut menunjukkan bahwa difuser dengan $\varnothing 160 \mathrm{~mm}$ memiliki unjuk kerja yang lebih handal pada tangki penyimpan energi termal stratifikasi.

\section{Daftar Pustaka}

1. S.K. Wang, Handbook of Air Conditioning and Refrigeration, $2^{\text {nd }}$ ed.Mc. Graw Hill Company, 2000.

2. A. Musser and W.P. Bahnfleth, "Field-Measured Performance of Four Full-Scale Cylindrical Stratified Chilled-Water Thermal Storage Tanks," ASHRAE Transaction vol. 105 (2), pp. 218-230, 1998.

3. J.H. Horlock, Cogeneration-combined Heat and Power (CHP): Thermodynamics and Economics, Pergamon, Oxford, England, 1987.

4. Waluyo Joko, Karakterisasi Distribusi Suhu Tangki Penyimpan Termal Stratifikasi dengan Persamaan Sigmoid Dose Response, Proceeding Seminar Nasional Tahunan Teknik Mesin XI (SNTTM XI) \& Thermofluid IV, Universitas Gadjah Mada (UGM), 2012. 